\title{
Neutralization of interleukin-17 produced by gamma delta $T$ cells constrains inflammation in experimental biliary atresia
}

Christian Klemann, Affl

Corresponding Affiliation: Aff1

Arne Schröder,, Affl

Anika Dreier, $\frac{\text { Affl }}{\underline{\text { na }}}$

Nora Moehn, $\stackrel{\text { Affl }}{\text { at }}$

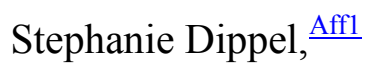

Thomas Winterberg, $\stackrel{\text { Affl }}{\text { f }}$

Anne Wilde, Aff1

Yi Yu, $\stackrel{\text { Affl }}{ }$

Faikah Gueler, $\stackrel{\text { Aff2 }}{\text { 2 }}$

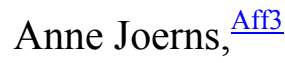

Eva Tolosa,, Aff4

Johannes Leonhardt, Aff5

Jan D Haas,, Aff6 Aff7

Present Affiliation: Aff7

Immo Prinz,,$\stackrel{\text { Aff6 }}{ }$

Claus Petersen,, Affl

Joachim F Kuebler, $\stackrel{\text { Affl }}{\text { f }}$

\begin{tabular}{|c|c|c|}
\hline \multicolumn{3}{|r|}{ ArticleInfo } \\
\hline ArticleID & $::$ & $\mid 61$ \\
\hline ArticleDOI & $:$ & || 10.1186/2194-7791-2-S1-A21 \\
\hline ArticleCitationID & $::$ & || A21 \\
\hline ArticleSequenceNumber & $::$ & $\mid 21$ \\
\hline ArticleCategory & $:$ & Meeting abstract \\
\hline ArticleFirstPage & $:$ & $\mid$\begin{tabular}{|l}
$\mid 1$ \\
1
\end{tabular} \\
\hline ArticleLastPage & $:$ & || 2 \\
\hline ArticleHistory & $:$ & \begin{tabular}{|ll} 
RegistrationDate & $: 2015-7-1$ \\
OnlineDate & $: 2015-7-1$
\end{tabular} \\
\hline
\end{tabular}




\begin{tabular}{|l||l|l||}
\hline \multirow{2}{*}{ ArticleCopyright } & & $\begin{array}{l}\text { Klemann et al.2015 } \\
\text { This article is published under license to BioMed Central } \\
\text { Ltd. This is an Open Access article distributed under the } \\
\text { terms of the Creative Commons Attribution License } \\
\text { (http://creativecommons.org/licenses/by/4.0), which permits } \\
\text { unrestricted use, distribution, and reproduction in any } \\
\text { medium, provided the original work is properly cited. }\end{array}$ \\
\hline
\end{tabular}

Aff1

Dept. of Pediatric Surgery, Hannover Medical School, Hannover, Germany

Aff2

Dept. of Nephrology, Hannover Medical School, Hannover, Germany

Aff3

Institute of Clinical Biochemistry, Hannover Medical School, Hannover, Germany

Aff4

Department of Immunology, University Medical Center Hamburg-Eppendorf, Hamburg, Germany

Aff5

Department of Pediatric Surgery, St. Bernward Hospital, Hildesheim, Germany

Aff6

Institute of Immunology, Hannover Medical School, Hannover, Germany

Aff7

MorphoSys AG, Martinsried/Planegg, Germany

Abstracts of the 51st Workshop for Pediatric Research

51st Workshop for Pediatric Research

Göttingen, Germany

16-17 April 2015

This supplement has not been sponsored.

Meeting abstracts

\section{Meeting abstract}

Biliary atresia (BA) is a rare disease of the infant with unknown pathogenesis. It is characterized by inflammatory, progressive destruction of the biliary system leading to liver fibrosis and progressive deterioration of liver function. Interleukin-17a (IL-17) has been identified as a cytokine driving inflammatory and autoimmune processes. We investigated the role of IL-17 and IL-17 producing cell populations in the pathogenesis of experimental and human BA.

In the rotavirus induced BA mouse model, symptomatic animals had a significantly increased hepatic transcription of IL-17. We identified gamma delta $(\gamma \delta)$ T cells as the exclusive source of IL-17, while classical Th17 cells were completely absent. The increased number of IL- $17^{+} \gamma \delta \mathrm{T}$ cells in $\mathrm{BA}^{+}$animals was associated with an up-regulation of typical markers of the IL-17-axis, such as IL17a, IL17f, ROR $\gamma \mathrm{t}$, CCR6 and the IL-23-receptor. In vivo, blockage of IL-17 by administration of monoclonal antibodies ameliorated the clinical course of disease, improved survival and serum bilirubin, and reduced liver inflammation.

In human infants with BA, hepatic transcription of IL-17 was significantly up-regulated compared to patients with 
other neonatal cholestatic diseases, while no differences in IL-17 levels were detected in patient sera.

Taken together, IL-17 released by lymphocytes bearing the $\gamma \delta$ T cell receptor appear to be a causative factor in the inflammatory destruction of the biliary system in experimental BA. Furthermore, our data suggest an important role of the IL-17 axis in human BA. Thus, targeting the IL-17 axis could be a promising approach for therapeutic interventions. 